\title{
Bioequivalence evaluation of two oral formulations of Dexketoprofen-trometamol (solution and tablets) in healthy subjects: Results from a randomized, single-blind, crossover study
}

\author{
Jorge González-Canudas, 2, , Luis Jesús García-Aguirre, Araceli Medina-Nolasco ${ }^{3}$, María Isabel Ruíz-Olmedo ${ }^{3}$, Liz Janet Medina Reyes ${ }^{3}$, \\ Lucia Zambrano Tapia ${ }^{3}$, Yulia Romero-Antonio ${ }^{2}$, Aarón Molina-Pérez ${ }^{2}$ and Ana Gabriela Amador-Hernández ${ }^{2}$ \\ ${ }^{1}$ IMSS-Centro Médico Nacional Siglo XXI, Mexico \\ ${ }^{2}$ Laboratorios Silanes, S.A. de C.V, Mexico \\ ${ }^{3}$ Investigación Farmacológica y Biofarmacéutica, S.A.P.I de C.V, Mexico
}

\begin{abstract}
This single-center, single-blind, randomized, 2-period, 2-treatment, crossover, single-dose-per-period, 2-sequence study evaluated the bioequivalence of a test dexketoprofen-trometamol (oral solution) compared with a reference $25 \mathrm{mg}$ dexketoprofen-trometamol in 27 healthy adults under fasting conditions. Blood samples were collected pre-dose and at specified intervals across an 8-hour period following administration and were analyzed for dexketoprofen-trometamol using a validated reverse-phase high-performance liquid chromatography method. Drug products were considered to be bioequivalent if confidence intervals of natural $\log$-transformed $\mathrm{C}_{\mathrm{max}}, \mathrm{AUC}_{0-\mathrm{t}}$, and $\mathrm{AUC}_{0-\infty}$ data were within the range of 80-125\%. Results showed an earlier $\mathrm{C}_{\max }$ which might traduce in faster onset of action for solution formulation. However, criteria for bioequivalence were met for $\mathrm{AUC}_{0-\mathrm{t}}$, and $\mathrm{AUC}_{0-\infty}$. All measured dexketoprofen-trometamol concentrations in this study were within a safe therapeutic range, and no adverse events were reported.
\end{abstract}

\section{Introduction}

Dexketoprofen-trometamol is a ketoprofen S enantiomer (+) that belongs to the Nonsteroidal anti-inflammatory drugs (NSAIDs) group with analgesic and anti-inflammatory actions and lower antipyretic effect that is effective for the symptomatic management of mild to moderate acute and chronic pain of diverse etiology. It is one of the more powerful inhibitors of prostaglandins synthesis [1-5].

The pharmacokinetic properties of dexketoprofen-trometamol have been studied previously in various populations. Dexketoprofentrometamol does not accumulates in fat tissue, its protein plasma union is about $99 \%$, medium distribution life is 0.35 hours and its distribution volume is under $0.25 \mathrm{~L} / \mathrm{Kg}$. In pharmacokinetics multiple dose studies, it has been observed that area under the curve for last sampling time $\left(\mathrm{AUC}_{0-\mathrm{t}}\right)$ does not differs from the one obtained for single doses, indicating that there is no an accumulation of the formula [6-8].

Absorption profile changes when it is ingested with food; its absorption time $\left(\mathrm{T}_{\max }\right)$ is increased from 0.63 to 1.5 hours and maximum plasma concentration $\left(\mathrm{C}_{\text {max }}\right)$ is reduced by $44 \%$, without alterations in the extension of absorbed drug. Nevertheless, anti-acid administration 10 minutes before has no effect over its $\mathrm{T}_{\max }$ and $\mathrm{C}_{\max }$. Dexketoprofen-trometamol absorption is bioequivalent to ketoprofen, even though its salt form it is slightly faster, its free acid form grade is significantly lower in comparison to ketoprofen [6-8].

Adverse events observed during clinical studies are those related to gastrointestinal origin, mainly nausea and vomit, but also diarrhea, constipation, flatulence, dyspepsia, abdominal pain, melena, hematemesis, ulcerative stomatitis, colitis exacerbation, Chron's disease, and less frequent gastritis. Coagulation parameters, including bleeding time, were not affected by the use of dexketoprofen-trometamol and there were no differences between placebo and reference values [6-10].

In Mexico, there are 5 products that contain dexketoprofentrometamol, either alone or in combination with other drugs, and in different strengths and dosage formulations; however, no oral solution was previously marketed in the country [11]. Oral solution formulations offer the advantage of easier swallowing for every patient, while the presentation in sachet is ready for use and allows patients to get their medication without necessarily using water or any liquid for deglution.

The objective of the current study was to evaluate the bioequivalence of a test dexketoprofen-trometamol available in Mexico (Velian;, $10 \mathrm{~mL}$ with $36.9 \mathrm{mg}$ of dexketoprofen-trometamol, equivalent to 25 $\mathrm{mg}$ of dexketoprofen; Laboratorios Silanes, S.A. de C.V., Mexico / Manufactured by Galenicum) compared with a reference product

*Correspondence to: Jorge González Canudas, Av. Paseo de las Palmas, \#340, Third Floor, Col. Lomas de Chapultepec, Alcaldía Miguel Hidalgo, C.P. 11000, Mexico, Tel: 5254883761; E-mail: jogonzalez@silanes.com.mx

Key words: Dexketoprofen-trometamol, bioequivalence, pain management, pharmacology

Received: January 19, 2019; Accepted: February 07, 2019; Published: February 11, 2019 
(Stadium; $36.9 \mathrm{mg}$ equivalent to $25 \mathrm{mg}$ of dexketoprofen-trometamol, equivalent to $25 \mathrm{mg}$ of dexketoprofen; Grimann, S.A. de C.V., Mexico) in healthy adults under fasting conditions.

\section{Methods}

The study protocol and the informed consent were approved by the Research Committee, the Research Ethics Committee and COFEPRIS (Federal Commission for the Protection against Sanitary Risks in Mexico). All study participants provided written informed consent. This single-center, single-blind, randomized, 2-period, 2-treatment, crossover, single-dose-per-period, 2 sequence study was designed to evaluate the bioequivalence of test and reference dexketoprofentrometamol products based on comparisons of pharmacokinetic parameters in healthy subjects. The study was conducted in accordance with the principles of the Declaration of Helsinki and its amendments [12], the International Conference on Harmonization Guideline for Good Clinical Practice [13], Guidance for Industry, Bioavailability and bioequivalence studies submitted in NDAs or INDs (FDA) [14], Administration's in vivo bioequivalence guidances [15], Guideline on the Investigation of Bioequivalence (EMA) [16] and Mexican bioequivalence guideline (Official Mexican Regulation NOM-177SSA1-2013 for establishing tests and procedures to prove drug products are interchangeable) [17].

\section{Subjects}

Healthy male and female volunteers between 18 and 55 years of age were eligible for study enrollment if they had a body mass index of 18.00 to $27.0 \mathrm{~kg} / \mathrm{m}^{2}$, were in a good state of health based on clinical history and safety laboratory parameters and were able and willing to comply with all study procedures and restrictions as evidenced by voluntary written informed consent. Study exclusion criteria included variations in vital sign measurements outside predefined limits or clinically significant abnormalities in the electrocardiogram at the screening visit; history of cardiovascular, renal, hepatic, muscular, metabolic, gastrointestinal (including constipation), neurologic, or endocrine disorders; history of dyspepsia, gastritis, esophagitis, or duodenal or gastric ulcers; history of hematopoietic disorders or any other type of anemia, asthma, mental illness, or any other organic abnormalities; or muscle trauma within 21 days before the study. Subjects were also excluded if they had taken any drug product, including vitamins or herbal remedies, within 30 days (or 7 half-lives) prior to the beginning of the study or required any drug product during the duration of the present study; had exposure to hepatic enzyme inducers or inhibitors, or drugs that alter urinary $\mathrm{pH}$, within 30 days before the study start; had used any other investigational product within 90 days before the study; had donated or lost $450 \mathrm{~mL}$ of blood within 60 days; had drug, food, or substance allergies or required a special diet; were unable to comply with study requirements; or had a history of or tested positive pregnancy test, or intended to become pregnant during the study. Employees of the sponsor or the study site members of their immediate families were also excluded.

To participate in the study, subjects were required to avoid alcohol, carbonated beverages, beverages containing xanthines (eg, coffee, tea, cocoa, chocolate and cola), coal-roasted food, grapefruit and orange juice, and smoking for 24 hours before the beginning of both study periods. In addition, from the time of the study selection visit until the end of the study, subjects were to avoid strenuous exercise, and subjects and their spouses were to avoid pregnancy from the time of study selection to 60 days after the last dose of study drug.

\section{Study design}

This was a randomized, single-blind, 2-period, 2-treatment, crossover, single-dose-per-period, 2-sequence study in healthy subjects under fasting conditions. The study was conducted at a single research center, Investigación Farmacológica y Biofarmacéutica (IFaB), in Mexico City, Mexico, in August 2015 (RNEC-Clinical Trials National Registry by its Spanish acronym-identifier: DXKTMT) [18].

Eligible subjects were admitted to the study center 24-hour $( \pm 2$ hours) for each of two periods that spanned from approximately 10 hours after study drug administration. Subjects were admitted to the study center the day before administration of the study drug between 5:00 pm and 9:00 pm. Shortly after admission to the study center, subjects underwent screening and physical examinations, received a light dinner, and were instructed to fast for a minimum of 10 hours prior to study drug administration at approximately 8:00 am the next day.

Subjects were randomized to 1 of 2 possible treatment sequences ( $\mathrm{AB}$ or $\mathrm{BA}$ ), In which treatment A consisted of a single $25 \mathrm{mg}$ equivalent dose of dexketoprofen reference product, and treatment $B$ consisted of a single $10 \mathrm{ml}$ ( $36.9 \mathrm{mg}$ equivalent to $25 \mathrm{mg}$ of dexketoprofen) of dexketoprofen-trometamol test product. Treatments were administered to subjects in a fasted state with $250 \mathrm{~mL}$ of room-temperature water. There was a 96-hour washout period between administration of the first and the second study drugs to ensure elimination of the first study drug.

Blood samples $(6 \mathrm{~mL})$ for pharmacokinetic analyses were collected over an 8-hour period based on the reported elimination half-life of dexketoprofen and variability in drug absorption after oral administration [3]. By taking samples over approximately 4 half-lives, it was expected that more than $90 \%$ of the administered drug would have been eliminated. In each study period, blood samples were taken pre-dose and at $0.08,0.16,15.00,0.25,0.50,0.75,1.00,1.25,1.50,1.75$, $2.00,2.50,3.00,4.00,6.00$, and 8.00 hours after administration of the study drug. At the final study evaluation, additional blood samples were taken for safety laboratory testing $(10 \mathrm{~mL})$ and liver function monitoring $(6 \mathrm{~mL})$.

Vital sign measurements (blood pressure, heart rate, respiratory rate, and body temperature) were taken at $02.00,06.00$ and 08.00 hours after administration of the study drug.

\section{Study assessments}

Blood samples (with a solution of citrate phosphate dextrose adenine added as an anticoagulant) were analyzed for dexketoprofen using a validated chromatographic method. Plasma dexketoprofentrometamol quantification was established by a protein precipitation extraction and separation technique by liquid chromatography through a reverse-phase column with ultraviolet detection using Dexketoprofen-d3 as an internal standard. The relationship between the chromatographic response with respect to concentration in each calibration curve was fitted by linear least-squares regression to the equation $y=m x+b$, with arrangement $1 / x^{2}$, where the " $y$ " variable was the ratio of the areas of dexketoprofen/Dexketoprofen- $\mathrm{d} 3$ (IS) obtained for the respective nominal concentration " $\mathrm{x}$ " of dexketoprofen.

Because of the sensitivity required for the characterization of the pharmacokinetic profile of dexketoprofen-trometamol, the analytical method was validated in the range of 100 to $7000 \mu \mathrm{g} / \mathrm{mL}$. The performance of the analytical run was evaluated with values obtained from the calibration and results of quality control samples. Each volunteer sample was integrated and quantified with the calibration 
curve on the day of the analysis; these curves met the linearity and accuracy parameters established during validation. Acceptance criteria for assay accuracy required intraday, interday, and reproducibility of reinjection percentage of absorption deviation to be $\leq 15 \%$, except for the lower limit of quantification, which was required to be $\leq 20 \%$. The acceptance criteria for baseline selectivity required that the analytical response of the interferences close to the retention time was $\leq 20 \%$ for the analyte of interest and $\leq 5 \%$ for the internal standard.

Analytical samples were stored in cryotubes at $-70^{\circ} \mathrm{C}$. Acceptance criteria for sample stability required that the percentage of absolute deviation was $\leq 15 \%$ relative to the value of recently prepared samples. Data showed that samples were stable for 4 freeze thaw cycles at $-70 \pm 10^{\circ} \mathrm{C}$; samples were also stable at room temperature $\left(15-30^{\circ} \mathrm{C}\right)$ for 22.3 hours and under refrigeration $\left(2-8^{\circ} \mathrm{C}\right)$ for 24.2 hours. The main dexketoprofen-trometamol standard solution was stable under refrigeration and frozen for 6 days.

Pharmacokinetic parameters determined based on plasma dexketoprofen concentration-time data included maximum plasma drug concentration $\left(\mathrm{C}_{\max }\right)$, time to achieve maximum plasma concentration $\left(\mathrm{T}_{\max }\right)$, area under the plasma drug concentrariontime curve, from time zero up to the last sampling time $\left(\mathrm{AUC}_{0-\mathrm{t}}\right)$ and extrapolated to infinity $\left(\mathrm{AUC}_{0-\infty}\right)$ and elimination half-life $\left(\mathrm{t}_{1 / 2}\right)$.

Safety was assessed by evaluating reported adverse events, abnormal clinical laboratory values, and changes in electrocardiogram parameters or vital signs during both study periods.

\section{Statistical analyses}

Sample size calculations were based on a dexketoprofen intrasubject CV of 20.55-30.35\%, which was observed in previous pilot studies in Mexican population [19]. Using a CV of 20.55-30.35\% for the main pharmacokinetic parameters of dexketoprofen $\left(\mathrm{C}_{\max }\right)$, the Shein-Chung Chow equation for crossover design was used to determine that a total simple size of 24 subjects were sufficient to demonstrate that bioequivalence of the test and reference dexketoprofen. To ensure that at least 24 subjects completed the study, the goal was to randomize 28 subjects [20].

Pharmacokinetic parameters were determined using noncompartmental methods and were summarized by treatment using descriptive statistics, including arithmetic mean, geometric mean, standard deviation, standard error, median, minimum, maximum, and $\mathrm{CV}$ for each variable. Natural log comparisons of the pharmacokinetic parameters of $\mathrm{C}_{\max }$ and $\mathrm{AUC}$ were performed for the test versus the reference drug using an analysis of variance model that included sequence, period, and formulation as fixed effects based on linear mixed effect models. Analysis of variance comparisons were performed using Phoenix/WinNonlin (Certara, LP, Princeton, New Jersey) considering the type III sum of squares.

Bioequivalence of the test and reference drug products was determined based on logarithmic comparisons of $\mathrm{C}_{\max }, \mathrm{AUC}_{0-\mathrm{t}}$, and $\mathrm{AUC}_{0-\infty}$. Drug products were considered to be bioequivalent if confidence intervals of natural log-transformed $\mathrm{C}_{\max }, \mathrm{AUC}_{0-\mathrm{t}}$, and $\mathrm{AUC}_{0-\infty}$ data were within the range of $80-125 \%$ with a confidence level of $90 \%$ and statistical power $>0.8$. The null hypothesis that the test and reference products were not bioequivalent was to be rejected on the basis of results of applied limit tests using Schuirmann's two 1-sided$\mathrm{t}$-tests and the Anderson Hauck test on the quotient of the averages of the tests to the reference drug products for $\mathrm{C}_{\max }, \mathrm{AUC}_{0 \mathrm{t}}$, and $\mathrm{AUC}_{0-\infty}$ if classic confidence intervals were not within the range of $80-125 \%$, with $90 \%$ confidence and alpha significance levels of 0.05 .

\section{Results}

\section{Subjects}

Twenty-eight subjects were randomly assigned to a treatment sequence, and 27 subjects completed the study. There were no major deviations from the study protocol. The study population included 12 (44\%) men and 15 (56\%) women; subject demographic and baseline characteristics are presented in Table 1.

Subjects received the study treatment by the allocated formulation sequence; 28 were included in safety evaluation and 27 in pharmacokinetic analysis.

\section{Pharmacokinetics}

The mean \pm standard error (SE) plasma concentration time profiles obtained after dexketoprofen-trometamol administation of oral solution or tablet are shown in Figure 1; mean plasma dexketoprofen concentration-vs-time curves were similar for the test and reference product.

Table 2 shows the $90 \%$ CI of the ratios (test/reference) for Logtransformed $\mathrm{C}_{\max }, \mathrm{AUC}_{0-\mathrm{t}}$ and $\mathrm{AUC}_{0-\infty}$ and the probability of exceeding the limits, as well as their statistical comparisons.

Table 1. Subject demographic and baseline characteristics

\begin{tabular}{|l|c|}
\hline Parameter & Value \\
\hline Sex $(\mathrm{n}, \%)$ & $13(46 \%)$ \\
\hline Male & $15(54 \%)$ \\
\hline Female & \\
\hline Age (years) & $29.3 \pm 7.83$ \\
\hline Mean \pm SD & $18-45$ \\
\hline Range & \\
\hline Body weight $(\mathrm{kg})$ & $62.5 \pm 6.83$ \\
\hline Mean \pm SD & $50.5-73.4$ \\
\hline Range & $1.62 \pm 0.07$ \\
\hline Height $(\mathrm{cm})$ & $1.4-1.7$ \\
\hline Mean \pm SD & \\
\hline Range & $23.73 \pm 1.74$ \\
\hline Body mass index $\left(\mathrm{kg} / \mathrm{m}^{2}\right)$ & $18.6-26.3$ \\
\hline Mean \pm SD & \\
\hline Range & \\
\hline
\end{tabular}

SD: Standard deviation; $\mathrm{N}=28$

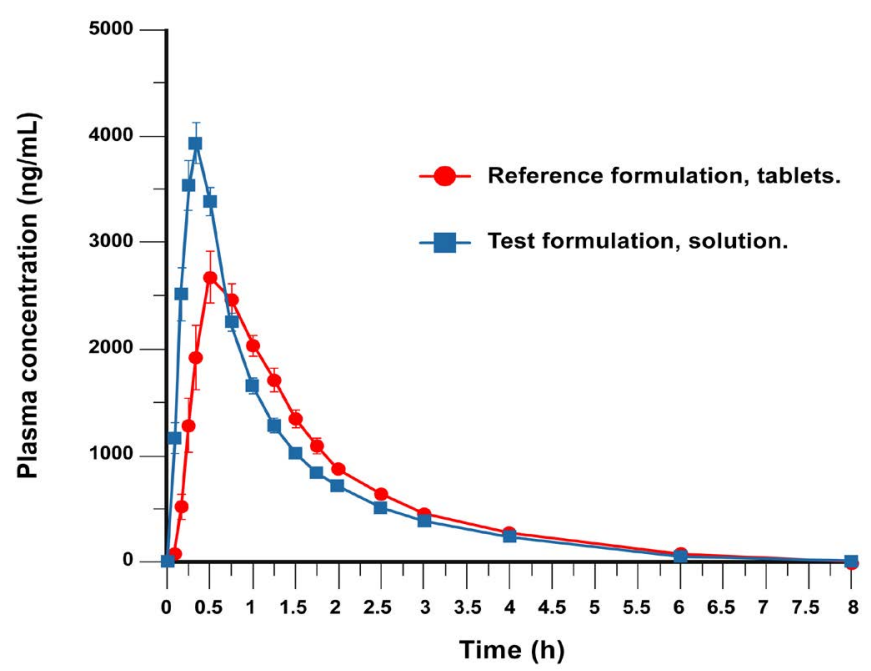

Figure 1. Time vs. plasma concentration 
González-Canudas J (2019) Bioequivalence evaluation of two oral formulations of Dexketoprofen-trometamol (solution and tablets) in healthy subjects: Results from a randomized, single-blind, crossover study

Table 2. Plasma pharmacokinetic parameters and statistical analysis results after single administration equivalent of $25 \mathrm{mg}$ of dexketoprofen, oral solution and tablet ( $\mathrm{N}=27$ )

\begin{tabular}{|c|c|c|c|c|c|}
\hline $\begin{array}{l}\text { Pharmacokinetic } \\
\text { parameter }\end{array}$ & $\begin{array}{c}\text { Reference } \\
\text { Formulation (tablet) } \\
(\text { mean } \pm \text { SD })\end{array}$ & $\begin{array}{c}\text { Test formulation } \\
\text { (oral solution) } \\
\text { (mean } \pm \text { SD) }\end{array}$ & PE \% & $90 \%$ CI & $\begin{array}{c}\text { Intrasubject } \\
\text { coefficient of variation }(\%)\end{array}$ \\
\hline $\mathrm{C}_{\max }(\mathrm{ng} / \mathrm{mL})$ & $3519.96 \pm 1049.88$ & $4329.80 \pm 879.42$ & 126.24 & $112.11-142.15$ & 25.9351 \\
\hline $\mathrm{AUC}_{0-\mathrm{t}}(\mathrm{h} \cdot \mathrm{ng} / \mathrm{mL})$ & $4444.31 \pm 743.76$ & $4685.13 \pm 899.48$ & 104.86 & $100.89-108.99$ & 8.3180 \\
\hline $\mathrm{AUC}_{0-\infty}$ (h.ng/mL) & $4772.94 \pm 762.26$ & $5065.79 \pm 944.96$ & 105.58 & $101.43-109.89$ & 8.6310 \\
\hline$t_{1 / 2}(h)$ & $1.31 \pm 0.25$ & $1.58 \pm 0.94$ & - & - & - \\
\hline $\mathrm{T}_{\max }(\mathrm{h})^{\mathrm{a}}$, median (range) & $0.50(0.33-1.25)$ & $0.33(0.16-0.75)$ & - & - & - \\
\hline $\operatorname{Ke}(1 / \mathrm{h})$ & $0.54 \pm 0.09$ & $0.48 \pm 0.10$ & - & - & - \\
\hline $\mathrm{MRT}_{0-\infty}(\mathrm{h})$ & $1.88 \pm 0.28$ & $1.74 \pm 0.69$ & - & - & - \\
\hline
\end{tabular}

$\mathrm{AUC}_{0-\mathrm{-}}:$ Area under the plasma drug concentration-versus-time curve from time zero to the last measurable-drug concentration; $\mathrm{AUC}_{0-\infty}: \mathrm{Area}$ under the plasma drug concentration-versustime curve from time zero extrapolated to infinity; $\mathrm{C}_{\max }$ : Maximum observed plasma drug concentration; CV: Coefficient of variation; max: Maximum; min: Minimum; SD: Standard deviation; $\mathrm{T}_{\max }$ : Time to $\mathrm{C}_{\max } ; \mathrm{t}_{12}$ : Limination half-life; $\mathrm{CI}$ : Confidence interval; $\mathrm{K}_{e}$ : Elimination rate constant; \%: Percentage; a: Comparison between tablet and oral solution by Wilcoxon signed-rank test: $p<0.01$; SS: Statistically significant

Maximum plasma concentration $\left(\mathrm{C}_{\max }\right)$ of dexketoprofen was $4329.80 \pm 879.42 \mathrm{ng} / \mathrm{mL}$ for oral solution (test formulation) and $3519.96 \pm 1049.88 \mathrm{ng} / \mathrm{mL}$ for tablet (reference formulation). $\mathrm{AUC}_{0-\mathrm{t}}$ values were $4685.13 \pm 899.48 \mathrm{~h} \cdot \mathrm{ng} / \mathrm{mL}$ (test formulation) and $4444.31 \pm 743.76 \mathrm{~h} \cdot \mathrm{ng} / \mathrm{mL}$ (reference formulation). $\mathrm{AUC}_{0-\infty}$ were $5065.79 \pm 944.96$ and $4772.94 \pm 762.26 \mathrm{~h} \cdot \mathrm{ng} / \mathrm{mL}$ for test and reference formulations, respectively. The ratios of test/reference geometric means (point estimate, PE \%) were $126.24,104.86$ and $105.58 \%$ for $\mathrm{C}_{\max }, \mathrm{AUC}_{0-\mathrm{t}}$ and $\mathrm{AUC}_{0-\infty}$, respectively, with their corresponding $90 \%$ CIs within the pre-specified acceptance limits for $\mathrm{AUC}_{0-\mathrm{t}}(100.89$ $108.99 \%)$ and $\mathrm{AUC}_{0-\infty}(101.43-109.89 \%)$ and outside the $80-125 \%$ range for $\mathrm{C}_{\max }$ (112.11-142.15\%). The peak concentration was rapidly reached, however oral solution was faster $(0.36$ and $0.63 \mathrm{~h}$ for test and reference treatments, respectively).

\section{Safety}

No adverse events were reported during this study in either treatment group.

\section{Discussion}

Dexketoprofen-trometamol oral solution has recently been marketed to meet the rising interest for formulations that offer improved absorption and quicker onset of action, without drinking, and that provide a more practical and user-friendly alternative relative to the marketed products for the treatment of mild and moderate pain.

Findings from this study showed that there were no significant differences between the test and reference dexketoprofen-trometamol products based on pharmacokinetic parameters associated with degree of drug absorption (ie, $\mathrm{AUC}_{0-\mathrm{t}}$ and $\mathrm{AUC}_{0-\infty}$ ). The $90 \% \mathrm{CI}$ were within the equivalence limits of $80.00-125.00 \%$ for $\mathrm{AUC}_{0-\mathrm{t}}$ and $\mathrm{AUC}_{0-\infty}$ and outside the pre-specified up limit for the peak concentration; probably because oral solution does not require releasing phase and might need a shorter time to achieve $\mathrm{C}_{\max }$.

The similarity in $\mathrm{t}_{1 / 2}$, elimination rate constant and mean residence time values obtained in this study confirmed that dexketoprofentrometamol, oral solution, presented similar elimination kinetics to dexketoprofen oral tablet after dosing.

A comparison of the present results with the literature data $[7,8]$, obtained after single dose administration of equivalent to $25 \mathrm{mg}$ of dexketoprofen during a bioequivalence study (oral solution vs. tablet), showed similar rate and extent of exposure with a favorable safety profile in both formulations.

As with any clinical trial, the current study had limitations that should be considered. Since data were obtained only from healthy subjects who received a single dose, the pharmacokinetic characteristic of dexketoprofen-trometamol might differ in target populations. As the study was done under fasting conditions, we are unable to predict the dexketoprofen-trometamol profile under fed conditions.

\section{Conclusions}

Study data shows that solution formulation has an earlier and higher peak exposure $\left(\mathrm{C}_{\max }\right)$ than the tablet formulation, and equivalent total exposure $\left(\mathrm{AUC}_{0-\mathrm{t}}\right.$ and $\left.\mathrm{AUC}_{0-\infty}\right)$. This might suggest earlier onset of analgesic effect that coupled with the swallowing advantage and the presentation in sachets for easier access and usage, represents an interesting option for acute pain treatment.

\section{Acknowledgments}

The authors would like to thank to Liz J. Medina Reyes and Lucía Zambrano Tapia for pharmacokinetics and biostatistical analysis and Olivia León Cardoso, for quality assurance during the study.

\section{Competing interests}

Author contributions to this article are as follows: study investigator: L.J.G.A., A.M.N.; enrolled patients: A.M.N.; study monitoring: Y.R.A.; collection and assembly of data: L.J.M.R.; analytic sampling process: M.I.R.O., L.Z.T; manuscripts preparation: J.G.C, A.M.P, A.G.A.H. data interpretation, manuscript review and revisions, and final approval of manuscript: all authors. J.G.C, Y.R.A, A.M.P and A.G.A.H are employees of Laboratorios Silanes, S.A. de C.V, and L.J.G.A., A.M.N., M.I.R.O., L.J.M.R. and L.Z.T. are employees of Investigación Farmacollógica y Biofarmacéutica (IFaB).

\section{Funding}

This study was entirely funded by Laboratorios Silanes, S.A. de C.V.

\section{References}

1. Vera P, Zapata L, Gich I, Mancebo J, Betbesé AJ (2012) Hemodynamic and antipyretic effects of paracetamol, metamizol and dexketoprofen in critical patients. Med Intensiva 36: 619-625. [Crossref]

2. Sagir O, Sunay FB, Yildirim H, Aksoz E, Ozaslan S, et al. (2013) Evaluation of the effects of dexketoprofen trometamol on knee joint: An in vivo \& in vitro study. Indian $J$ Med Res 138: 912-918. [Crossref]

3. Pubchem (2016) Dexketoprofen trometamol. Accessed on July 20th, 2016. http:// pubchem.ncbi.nlm.nih.gov/compound/177976\#section=Top.

4. Hanna M, Moon JY (2018) A review of dexketoprofen trometamol in acute pain. Curr Med Res Opin. [Crossref]

5. Kayipmaz AE, Giray TA, Tasci SS, Tasci SS, Kavalci C, et al. (2015) Acute dystonic reaction due to dexketoprofen trometamol. J Pak Med Assoc 65: 1231-1232. [Crossref]

6. Barbanoj M, Antonjoan R, Rico S (2008) Dexketoprofeno trometamina: Evidencia clã nica apoya su eficacia como analgésico. Expert Rev Neurother 8: 1625-1640. 
7. Truven Health Analytics Inc (2016) Micromedex data base. Accessed on July 20th, 2016 http://www.micromedexsolutions.com/micromedex2/librarian/PDFefaultActionId/ evidencexpert.DoIntegratedSearch.

8. PLM (2016) Stadium. Accessed on July 20th, 2016. http://www.medicamentosplm. com/home/productos/stadium_tabletas/160/101/9884/210.

9. Laporte J, Ibanez L, Vidal X, Vendrell L, Leone R (2014) Upper gastrointestinal bleeding associated with the use of NSAIDS: Newer versus older agents. Drug Saf 27: 411-420. [Crossref]

10. Goday-Bujan JJ, Rodríguez-Lozano J, Martínez-González MC, Fonseca E (2006) Photoallergic contact dermatitis from dexketoprofen: Study of 6 cases. Contact Dermatitis 55: 59-61. [Crossref]

11. COFEPRIS (2016) Buscador Público de Registros Sanitarios. Accessed July 20th, 2016. http://tramiteselectronicos02.cofepris.gob.mx/BuscadorPublicoRegistrosSanitarios/ BusquedaRegistroSanitario.aspx

12. World medical association declaration of Helsinki: Ethical principle for medical research involving human subjects [WMA web site]. Adopted by the 18th WMA general assembly, Helsinki, Finland, June 1964, and amended by the 52nd WMA general assembly, Edinburgh, Scotland, October 7, 2000. Accessed April 18th, 2016. http://www.wma.net/.

13. European agency for the evaluation of medicinal products, International conference on harmonisation- World health organization. Guideline for good clinical practice [EMEA Web site]. ICH topic E6. Geneva, Switzerland: WHO; 2002. Accessed April 2016. Available at: http://www.emea.europa.eu.
14. Center for drug evaluation and research (CDER) (2014) Food and drug administration. Guidance for industry. Bioavailability and bioequivalence studies submitted in NDAs or INDs- General Considerations. pp: 1-26.

15. US food and drug administration (1993) In vivo bioequivalence guidances Pharmacopeial Forum 19: 6501-6508

16. European medicines agency (2010) Guideline on the investigation of bioequivalence. Committee for medicinal products for human use. pp: 2-27.

17. Health secretary. Official Mexican Norm NOM-177-SSA1-2013. DOF: 20.09.2013 Mexico. Accessed on April 2016. http://www.dof.gob.mx/nota_detalle.php?codigo=5 $314833 \&$ fecha $=20 / 09 / 2013$.

18. RNEC (2016) Consultas de ensayos clínicos registrados. COFEPRIS Accessed April 2016. http://siipris03.cofepris.gob.mx/Resoluciones/Consultas/ ConWebRegEnsayosClinicos.asp

19. Garcia-Arieta A, Gordon J, Gwaza L, Mangas-Sanjuan V, Álvarez C, et al. (2015) Agitation rate and time for complete dissolution in BCS biowaivers based on investigation of a BCS biowaiver for Dexketoprofen tablets. Mol Pharm 12: 31943201. [Crossref]

20. Shein-Chung C, Jen-epi L (2009) Design and analysis of bioavailability and bioequivalence studies. Chapman\&Hall/CRC.

Copyright: (C2019 González-Canudas J. This is an open-access article distributed under the terms of the Creative Commons Attribution License, which permits unrestricted use, distribution, and reproduction in any medium, provided the original author and source are credited. 